\title{
Evaluating the information value of tactile maps
}

\author{
Jakub Wabiński *, Albina Mościcka, Marta Kuźma \\ Military University of Technology,JakubWabiński,jakub.wabinski@wat.edu.pl, Albina Mościcka,albina.moscicka@wat.edu.pl, \\ Marta Kuźma, marta.kuzma@wat.edu.pl \\ * Corresponding author
}

Keywords: tactile maps, information value, 3D printing, map assessment, blind and visually impaired

\begin{abstract}
:
People who are blind or visually impaired use tactile maps, read by the sense of touch. In this research we assessed the information value of tactile maps, i.e. the extent to which the map reader gains the intended/needed information from the map. Methods usually used for assessing traditional (visual) maps have been adopted to evaluate two tactile maps presenting the same phenomenon but produced using different techniques: transparent relief print imposed on a colored base and $3 \mathrm{D}$ printing.
\end{abstract}

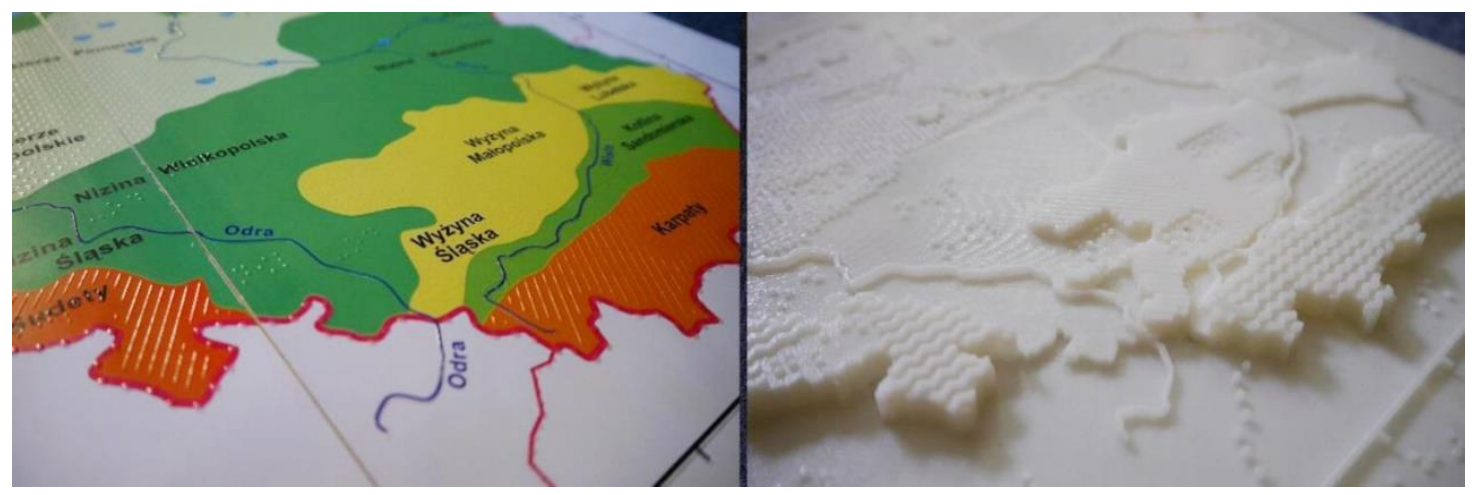

Figure 1. The maps used in the research.

In order to assess the information value of tactile elements on both maps, we have calculated structural measure of information, in a way proposed by Salistchev that bases on methods of mathematical information theory, and the information efficiency coefficient of a map, proposed by Grygorenko.

This research was motivated by two research questions:

1. How does the production method used affect the cartographic information value of the tactile map?

2. Can the methods for computing map information value on traditional maps be applied to tactile maps?

The results suggest that use of 3D printing, or any other manufacturing technology that allows full freedom in height differentiation of cartographic signs, makes it possible to increase the information value of a particular tactile map. This might allow tactile cartographers to design cartographic materials of higher value and to distribute the map content in a more efficient way.
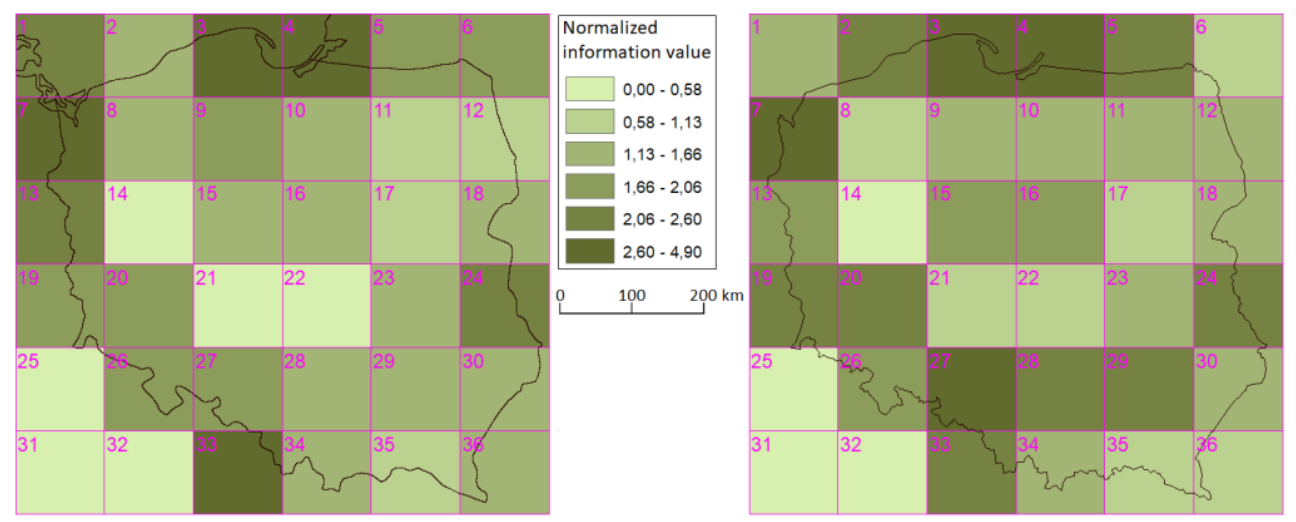

Figure 2 Distribution of the values of structural measure of information.

Left - original map from the atlas, right - 3D printed map. 